\title{
Innovacq implementation:
}

\section{A reference librarian's perspective}

\author{
By Mary Woodward
}

Law Librarian

University of New Mexico Law School

\section{Automating serials in an academic law library.}

I

$\mathrm{n}$ the past decade academic libraries have

been turning to automated serials control systems. Such systems have been particularly effective in university law libraries due to the high proportion of serials to monographs in the colllection. At the University of New Mexico Law Library, over $90 \%$ of the materials budget is devoted to the purchase of serial titles.

The switch from a manual to an automated system can be a tedious and problem-riddled task. Nonetheless, both serials and reference departments are discovering that the result, with easily accessible, uniform records that show check-in information and expected dates of arrival, is well worth the struggle.

Innovacq, created by Innovative Interfaces in Berkeley, is the automated serials control system selected by the University of New Mexico School of Law Library to convert its 4,000+ serial records. The Law Library shares Innovacq with the general academic library on campus, but each library maintains its serials records separately. Several previous articles in the library literature have pointed out the success of Innovacq. While this article will review Innovacq's strengths, it will also describe how the Law Library made the transition to Innovacq.

The University of New Mexico Law Library began using the Innovacq Serials Control System in July 1987. Approximately $40 \%$ of the serials check-in records as well as the majority of pay records were not converted to Innovacq until December 1988-August 1989. During this period, the combination of new technology, minimal advance planning, and many changes in staffing and organization led to some frustration for the reference staff in using the system. A terminal was located in the Reference Center from the project's inception, but that didn't eliminate the need for the reference staff to contact Technical Services frequently for Kardex or OCLC information on titles. Despite these first two years of incomplete information, the realization was always present that Innovacq could greatly improve and simplify reference services.

I was given the opportunity by Jami Hotsinpiller, reader services librarian, to divide up my reference position. Part of my time was spent performing reference services, and the remainder was devoted to completing the implementation of the Innovacq system. This proved to be an excellent introduction to legal materials.

\section{Converting manual records}

Initially my goal seemed straightforward: to add every remaining current serial title into Innovacq, and to build the check-in records for each title and its parts. Before long I was immersed in Kardex trays, OCLC notebooks containing a partial history of our serials holdings, and lapsed titles by the hundreds. To compound the difficulties, the manual claiming system had fallen by the wayside be- 
cause of frequent staff turnover. The project quickly branched into three projects: 1) inputting and building serials records on Innovacq; 2) making sure lapsed titles were reviewed by subject selectors and reinstated if still needed; and 3) using Innovacq's automatic claiming function.

Converting serials records involved downloading MARC records from OCLC to Innovacq and then building the check-in record(s) that attach to the bibliographic record. In the course of this project, many title problems and idiosyncrasies were revealed. This necessitated recataloging, additional ordering, and general problem-solving.

Although traditional journals and annual publications are considered serial titles in a law library, many other formats are referred to as serials, too. Looseleaf service binders receive weekly pages to be interfiled; reporter advance sheets arrive weekly or monthly to supplement a bound volume; pocket parts are annual supplements added to the inside back cover of a bound volume. Because currency of these services is critical, most of them had been placed on Innovacq first, before this project began.

To avoid titles lapsing inadvertently, we decided to build records for all titles by going though each kardex and each title in our OCLC notebooks of holdings. Checking the OCLC notebooks was necessary because the UNM Law Library had been in the process of switching from a kardex to an OCLC Serials Control System prior to Innovacq. When Innovacq was installed, we were in the middle of maintaining two different serials holding lists.

One of the first problems we encountered using Innovacq was our failure to locate existing records because of inexact title information. Innovacq allows unlimited alternate titles to be added to a bibliographic record. As we built records and checked in materials we made a concerted effort to add any alternate title that we found helpful. Members of the reference staff were able to send suggested alternate titles by way of a "change request form" to the serials staff, who added the title information to the bibliographic record.

Another of our growing problems was due to our sharing the Innovacq system with the general library on campus. When we searched for a title like the New York Times, we were greeted with a preliminary screen of seven choices for that title. It was time-consuming to select each of these records to determine which was the Law Library's. The author field was displayed on this screen along with the title field and, since for many serials the author field is blank, we used that line to add the location. We can now see from the preliminary screen which record we want to view. In the cases where an author did exist in a record we added "LAW" after the author's name. We identified our records only if both libraries owned the same title.

\section{Lapsed titles}

As we continued to download and build Innovacq check-in records, each title was examined. Records were set aside that appeared to have lapsed unintentionally. Once there were a sufficient number of lapsed titles to be reviewed, we printed out lists of these titles with whatever publishing and subscription information we had. Each list contained about 200 titles that were coded for the appropriate subject selector. During the summer of 1989 more than ten lists of lapsed titles or 2,000 titles were reviewed by selectors.

When a title received a "renew" decision, it was sent to the Acquisitions Department to be ordered. That department also distributed a cumulative list of lapsed title decisions from time to time. Decisions and dates were added to the Innovacq checkin screen so that the serials check-in staff member could determine when to send a title to a selector for another review.

Records for a few lapsed titles that received renew decisions were already on Innovacq. Checkin records for those items were revised and notes added. For most lapsed titles though, records had to be downloaded and built. If items received a "cancel" or "let lapse" decision, a note was added to the few records already on Innovacq.

Many titles had lapsed over the years at the Law Library because no consistent claiming procedure had been in place. Essentially, individual titles were claimed when someone noticed they were missing. By using Innovacq's automatic claiming function, we have solved most of our problems with claiming and lapsed titles. The claiming function was easy to set up and use, although processing the actual claims is time-consuming.

During this final implementation of Innovacq we decided to switch from a jobber for serials who didn't specialize in legal publications to one who did. We also had many direct subscriptions to journals that should have been handled by one jobber. Consolidating orders eventually greatly simplified claiming.

\section{Automatic claiming}

When check-in records are built on Innovacq, the option is provided for setting the dates of a title's projected arrival. For example, a law review may be sent on a quarterly basis, usually arriving in January, April, July, and October. We prepared to use Innovacq's claiming function by setting these dates on Innovacq, and also by adding a number of days (30 for most law reviews) when a late notice should flash in the journal issue's check-in box. We then had to separate all of the Law Library records from the records of the other campus library with which we share space on Innovacq. Finally, all our 


\section{FES INDEX plus TEXT on COMPACT DISC}

\section{Developed for Public and Academic Libraries}

Indexes, abstracts and full text ...

- for all manufacturing and service industries

a from more than 1,000 key business and trade publications

- covering North America, Europe, Latin America and the Pacific Rim

- available with SilverPlatter Information Retrieval Software

Plus, you own the annual archival disc, and there's no extra charge for LANs!

\section{For more information and a free brochure, call Predicasts today!}

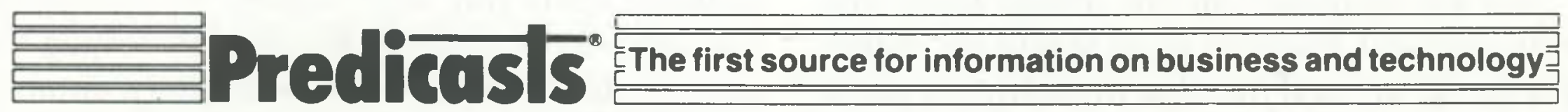

North America: 11001 Cedar Avenue / Cleveland OH 44106 / (216) 795-3000 / (800) 321-6388 / Fax (216) 229-9944 Europe: 8-10 Denman Street / London W1V 7RF United Kingdom / (071) 494-3817 / Fax (071) 734-5935 
records were placed in a file which was saved to one of the Innovacq terminal's storage slots.

To initiate claiming now, we recall this file weekly and look at each record that contains at least one box flashing “LATE.” These records with late issues automatically appear on the screen when in the claiming function. We then determine from what we know about that title whether a claim should be mailed.

For major publishers we keyed the publisher's code and address information into Innovacq. This information prints out on the claim slip.

If an item continues to be late after a claim is mailed, a "CLAIM1" or "CLAIM2" message flashes repeatedly in the check-in box. Second and third claims are generated as needed.

A claim may be generated for individual titles even when the system is not in the claiming function, although the automatic prompt to do so appears only in the check-in mode. When pulling up an Innovacq record a staff member may notice an item has a "LATE" message flashing. At the Law Library, only the serials staff generates claims but reference may send serials the "change request form" inquiring about a late issue.

\section{Reference use of Innovacq}

As Innovacq was brought up-to-date with all the latest and most complete information, the reference staff began to rely heavily on the system. At the same time, we wanted to get all the latest billing information into Innovacq so that became a project for the Acquisitions Department. By June 1989 all prior billing information had been added to Innovacq, including renewal or lapsed title information and coding by subject funds.

One of our procedures that changed after having Innovacq in place was payment of invoices or the inputting of data about payment. Originally, invoices that arrived with an item the Library intended to keep were sent to Administration/Acquisitions with the Innovacq pay record number. Administration staff then input the invoice number, pay date and price/number of copies. To eliminate delays, the serials check-in staff began to enter this data for items with invoices. The invoice showing that Innovacq now contained the pay data was sent on to the administration staff, who could then request the check.

After two years of record building on Innovacq and several changes in staff, we felt many inconsistencies existed from record to record. In the attempt to make every record (both check-in and pay) as uniform as possible and also to familiarize the entire reference staff with Innovacq, our Acquisitions Department printed out check-in and pay record screens for each record. For several months, the reference staff compared each printout to a model printout marking changes in red. These printouts were subsequently used to create improved records.

Currently, we depend upon Innovacq to supply much information to the reference staff: call numbers, alternate titles and title changes, copies and locations, publisher, lapse or renewal decisions, gift status of a title, previous holdings, current subscription problems, late issues, expected dates for subsequent issues, number of copies paid for, the cost of a current pocket part, the selector responsible for a title's purchase. By checking an Innovacq record, reference staff can also determine if a missing item has been checked in and been routed to faculty or staff thus delaying its appearance on the shelf.

Although Innovacq check-in records have been set up mainly for serial titles, abbreviated or "dummy" records for recently purchased monographic titles have been added with pay records. Now it is possible to see if a new monograph has been ordered and/or received. The card catalog (soon to be replaced by an online catalog) is still the last place to go for call numbers of older serials that have folded and older monographs, but Innovacq has become the first and most desirable place for reference to check on current materials.

Innovacq can also be used to create various types of lists or reports depending on how records are coded. Our Acquisitions Department sends reference periodic "on order" (arranged by selector) and "new titles received" lists providing us with the latest purchasing information. We also can print a list of gifts from professors enabling us to send notes of appreciation to our faculty.

Our serials staff has recently discovered that Innovacq can be used to create a list of missing items. Over the years we had maintained manual lists of missing or lost serials. With Innovacq in place it was difficult to continue checking manual lists, and these lists were becoming outdated. By inserting the word "missing" into an item's note field we can run a boolean search for that word and create a list. We search the Law Library's claiming file to avoid finding missing items from the other campus library's records.

Also, as missing items are received and checked in it is evident from the note field why they have been sent to the Law Library. The remaining Innovacq function to implement is the bindery function. Once the option is set up and running we feel reference will have little reason to call down to Technical Services, and operations will be less interrupted in general. When the bindery function is in place with previous bound holdings updated, Innovacq will be complete. 


\section{Conclusion}

As a member of the reference staff, $I$ feel very lucky to have had the opportunity of working closely with the Innovacq project. It may not be a viable option for most law libraries to allow a reference librarian to devote so much time to technical service projects but I feel it has greatly improved not only my use of Innovacq but more importantly my knowledge of the law library procedures and holdings. I have a grasp of serials and their nuances that I would never have possessed had I not done this project. The Innovacq project was, in a sense, a crash course on law library publications and interdepartmental cooperation.

The transition from a manual to an automated system of serials control, or in the UNM Law Library's case, from kardex to Innovacq, can be tumultuous. Initially, it can appear to dredge up more problems than it resolves, and depending on how much planning was done prior to installation, con- version itself can extend over several years or more. Despite the upheaval and length of time required to fully implement an automated system, a new serials control system provides an opportunity to solve the many problems that may riddle the existing system. Prior to a transition is the perfect time to examine problems that have rolled over from year to year: for example, inconsistencies in holding records, bound runs, bibliographic and check-in information, cataloging decisions or recurring subscription/vendor issues. In order to benefit from a new system you must make sure that the existing records are accurate before transferring the information to an automated system. Cleaning up the present system while making the transition to Innovacq may not have been in the planning initially at UNM, but it wasn't long before it became part of the process. And now at the project's completion, we feel we have not only made the transition but have a clean system to work with as well.

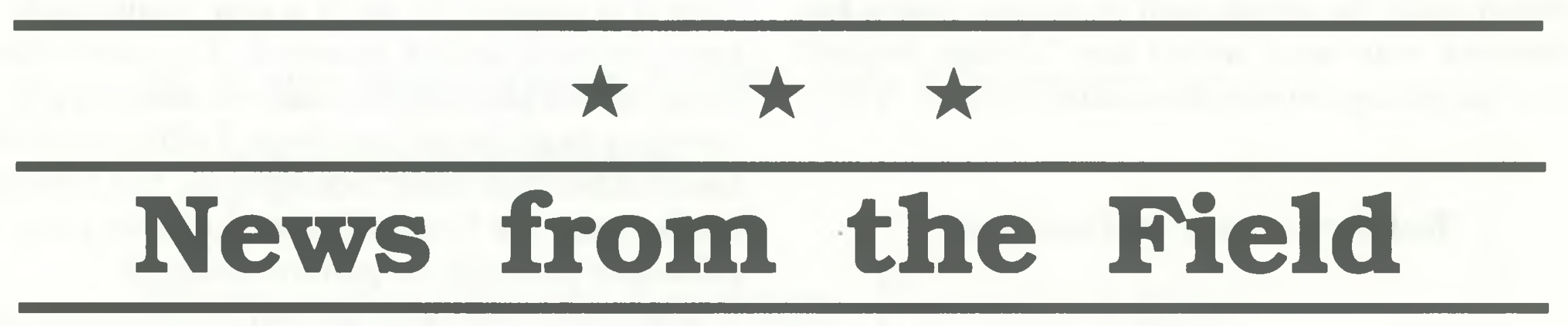

\section{Acquisitions}

- Louisiana State University's Louisiana and Lower Mississippi Valley Collections, Baton Rouge, have acquired an extensive group of manuscripts documenting several generations of the Mathews and Butler families. Consisting of more than 4,500 items, spanning the years 1811 to 1945 , the manuscripts detail the accounts and affairs of sharecroppers and tenants from at least six different plantations. Subjects documented vary widely from black labor and history, ecclesiastical history, engineering and agricultural projects, to natural history and bird watching. The papers were acquired with the support of the LSU Friends of the Libraries.

- The University of Rochester School of Medicine \& Dentistry's Edward G. Miner Library, New York, has received the papers of John Romano, M.D. Romano was the founding chairman of the Department of Psychiatry at Rochester, and an influential figure in American psychiatry and in the development of medical and psychiatric education. The Romano papers span the period from 1928 to 1989. The collection includes extensive files of personal and professional correspondence; the minutes, reports and memoranda of the University committees on which he served; records of the Department of Psychiatry (1946-1971); nearly 50 years of clinical rounds; and a large collection of personal and historical prints and photographs.

\section{Grants}

- The Center for Research Libraries, Chicago, has been awarded $\$ 95,080$ in outright funds by the National Endowment for the Humanities to improve bibliographic access to its microform holdings. The grant will enable the Center to disseminate bibliographic information about the monographic holdings of its materials in the Cooperative Africana Microform Project and titles in commercially produced microform sets. Records for monographic titles will be added to two international bibliographic databases. Approximately 13,000 records will be converted into machine-readable form, added to the OCLC database, and eventually tapeloaded into the Research Libraries Information Network database.

- $\underline{\text { The Ponce Technological University }}$ 